\title{
Recalling good memories
}

\author{
D Masopust $^{1}$ and V Vezys ${ }^{1}$
}

Our chief want in life is somebody who will make us do what we can.

-Ralph Waldo Emerson

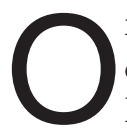
n 20 July 2013, the immunology community unexpectedly lost Leo Lefrançois. Leo was a pioneer in mucosal T-cell biology and immunological memory and very much in the prime of his research career. The field mourns his premature passing, the loss of the discoveries that he would have made, the ideas he would have inspired, and his straight-shooting but infectious personality.

Leo displayed an early aptitude for science. He obtained his PhD at Wake Forest University in only 2.5 years, while publishing many highly cited works characterizing mouse immune responses to vesicular stomatitis viruses. He provided additional evidence of his talent during postdoctoral training with Michael Bevan at Scripps. There, Leo published several papers, including one in Nature, while honing his scientific method, developing important collegial relationships, and cementing his lasting interest in CD8 T-cell memory. But it was only after taking an independent position, at the Upjohn Company in Kalamazoo, Michigan, that Leo developed his lifelong passion for mucosal immunology. During his brief tenure at Upjohn, Leo made a series of seminal discoveries. He reported that

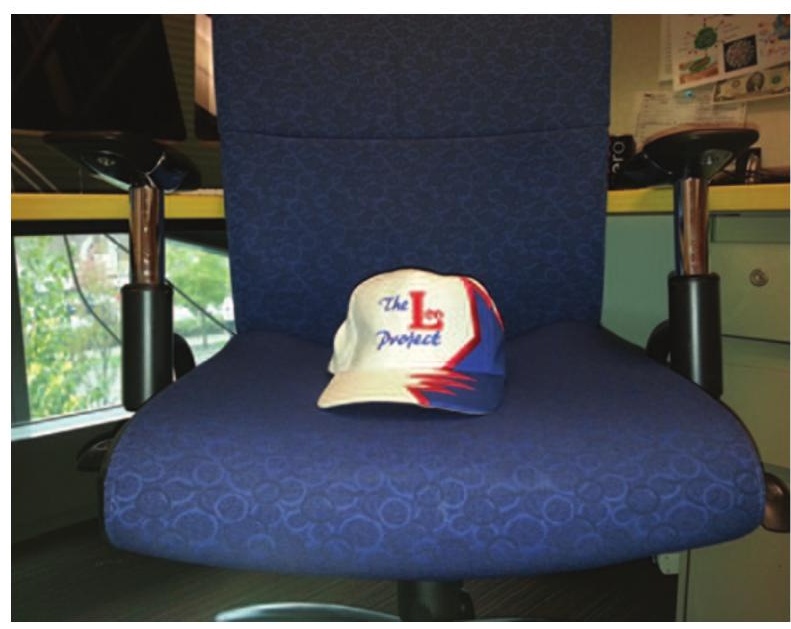

Leo's "The Leo Project" hat watches over a former trainee and keeps him on point.

$\mathrm{TCR} \gamma \delta^{+} \mathrm{T}$ cells were highly enriched in the intestinal mucosal epithelium, that they were constitutively cytolytic, and that they can develop even in the absence of a thymus. This work launched a long career in the study of anatomically restricted T-cell populations and their phenotypic specialization within the intestinal mucosa.

Leo was always quick to adopt the latest technological innovations, and he pioneered the analysis of antigenspecific antiviral T-cell responses in the gut. In many ways, he was far ahead of his time. Leo reported that acute infections establish TCR $\alpha \beta^{+} \mathrm{T}$ cells within the intestinal mucosa (and other nonlymphoid locations), where they adopt site-specific phenotypic signatures and functions. He was

${ }^{1}$ Department of Microbiology and Center for Immunology, University of Minnesota, Minneapolis, Minnesota, USA 
The last time we saw Leo was at the American Association of Immunologists annual meeting in Honolulu in May 2013. Leo had given a rousing talk on resident memory $\mathrm{T}$ cells, a field he helped pioneer. His current and former trainees all gathered for dinner that night. A group of former trainees sat with Leo, and they laughed and laughed; it was immediately like old times. We (Vaiva and Dave) were now married, and we consider those who were in our generation in Leo's lab to be dear friends. The thought that we would lose Leo so soon never crossed our minds.

As we reflect on what made Leo's lab so special, we feel it was his ability to stoke love and passion for science. It is said that one should lead by example. Leo's excitement about science was clear to see, and this was imprinted on us. By providing direction but allowing intellectual freedom, he empowered the people who worked with him. As a consequence, they learned to become independent thinkers. It is remarkable how many of Leo's trainees have successful careers in industry or government or run university research labs. These days, being successful in science requires a total commitment; it is not a 9-to-5 job. Therefore, embracing it for the creative art that it is and learning to tolerate the constant critiques, competition, and stressed resources, while being consumed by the thrill of discovery and the humanity of cooperative research, are essential. These are the lessons we learned from Leo. It is easier said than done, but as we manage our own labs it is this spirit that we try to maintain and pass on.

Leo had many great friends in the field of immunology. We were among the very fortunate who got to train with him and to engage and grow and discover together on a daily basis. For that we are forever grateful. And the Leo Project will live on.

(C) 2014 Society for Mucosal Immunology 